much to say that the interpretation of vital phenomena is merely a question of the successful application of chemistry and physics to living protoplasm, but it is certain that in the future chemistry and physics will piay a part of constantly increasing importance in the solution of biological problems.

A. D.

\section{SPECTROSCOPIC RESEARCHES.}

TWO useful papers on the arc spectra of iron and titanium, respectively, appear in the March number of the Astrophysical Journal. At the suggestion of Prof. Fowler, Mr. E. J. Evans, of the Imperial College of Science and Technology, undertook the investigation of the less refrangible portions of these spectra, which are especialiy important because of the sun-spot visual observations made in the red end of the spectrum. Mr. Evans now gives the wave-lengths for the iron. lines between $\lambda 6855$ and $\lambda 7412$, and for the titanium lines from $\lambda 5^{866}$ to $\lambda$ 7364. For the iron spectrum Rowland had previously given wave-lengths to 6855 , whilst Hasselberg had fully investigated the titanium spectrum more refrangible than 5899; Rowland's and Thalén's lists of lines beyond 5899 are incomplete, and it was to fill the lacunae that the present investigation was prosecuted. The photographs were taken, either with a Littrow prismatic spectrograph of 12 feet focal length or with a Rowland concave-grating spectrograph of 10 feet radius and I4,500 lines, on "panchromatic" plates, and in the iron spectrum show about ninety lines less refrangible than $\lambda 6855$, for sixty-seven of which wave-lengths and intensities are given. Wavelengths and intensities are similarly tabulated for Ioo titanium lines less refrangible than $\lambda$ 5866, and in both cases the nearest lines in Rowland's list of solar wavelengths are given for comparison. Of the titanium lines, only twenty-four were ascribed to titanium, or titanium mixtures, by Rowland, and some of those now given are recognised as "fluting" lines found by Hale and Adams in the red end of the sun-spot spectrum.

Until the publication of a recent research by Prof. Wood, the greatest number of lines recognised in the series of spectral radiations of any one element was twenty-nine, which Evershed found in the hydrogen spectrum of the solar chromosphere. In the case of sodium, only seven lines belonging to the principal series were known previously to the results now published by:Prof. R. W Wood. In a paper recently published in the Philosophical Magazine he gave provisional wave-lengths for twentyfour lines, and suggested that a large increase of dispersion might reveal many more lines of this series. Having employed greater dispersion, he now gives, in No. 2, vol. xxix., of the Astrophysical Journal (p. 97), the wave-lengths of forty-eight lines, thus enabling the Balmer formula to be tested up to $n=50$. Even now there are indications that a yet larger dispersion would extend the series still further. The need for a large dispersion in this work is strikingly illustrated by the fact that the last twenty-two lines now given fall in a region of the spectrum not wider than the distance between the $\mathrm{D}$ lines: the wave-length of the twenty-ninth line of the series is 2420.02 , whilst that of the fifticth is 2414.50 . One point of special interest disclosed by Prof. Wood's research is that, with very dense sodium vapour, there is an exceptionally strong general absorption extending from the head of the Balmer series to the end of the ultra-violet, that is to say, the vapour is much more transparent to the light between the absorption lines than it is beyond them. So marked is this that the head of the series actually shows brighter than the rest of the more refrangible spectrum.

\section{UNIVERSITY AND EDUCATIONAL} INTELLIGENCE.

Miss Mary $T$. Fraser, student at the South-Western Polytechnic Institute, Chelsea, has been elected to the Lindley studentship, University of London. The studentship is awarded to a student qualified to undertake research in physiology, and is held in the physiological laboratory of the University. The amount of the studentship is rool.

UNDER the terms of the charter of the University of School, the committee of the Department of Technology,

Bristol, the faculty of engineering of the University will be provided and maintained by the Society of Merchant Venturers in their technical college. The principal of that college, Prof. J. Wertheimer, will be ex officio dean of the faculty, and will also hold the post of professor of applied chemistry in the University, while the following professors in the technical college will hold corresponding posts in the University, viz. :- Prof. J. Munro, professor of mechanical engineering; Prof. E. S. Boulton, professor of applied mathematics; Prof. D. Robertson, professor of electrical engineering; and Prof. W. Morgan, professor of motor-car engineering. Mr. F. R. B. Watson will hold the post of lecturer on mechanical engineering, and $\mathrm{Mr}$. H. A. M. Borland that of lecturer on applied chemistry.

THIS year St. Paul's School reaches her 40oth anniversary. The event will be celebrated by an addition of large and excellently furnished new laboratories to the present buildings. These are already nearing completion, and will be officially opened on July 7 by Lord Curzon. The distant scparation of the existing physical and chemical laboratories has afways been a difficulty, and the limits of the former have been tried to their utmost. The new building has a frontage of 100 feet. It is of red brick, and forms a handsome annex to the big school; its inner walls are lined with white tile. The ground floor will be devoted to physics, the upper floor to chemistry. There are three working rooms on both floors, and each will play the several parts of class-room, lecture-room, and laboratory. Between the large and the two small laboratories there are preparation and store rooms. Two large rooms, one on each floor, measure 40 feet by 50 feet, the smaller ones 40 feet by 25 feet. They will be equipped, respectively, to meet the requirements of beginners, more advanced students, and those preparing for the universities and hospitals. There will thus be accommodation for ${ }^{1} 30$ students, with everything immediately at command. Especial care has been taken to keep the chemical rooms free from noxious fumes; air circulation is kept up by powerful fans, while all the draught cupboards have immediate communication with the outer air. Experiences gained in many of our new laboratories have been freely drawn upon in constructing and furnishing this building, and neither time nor money have been spared to assure fulfilment of its object.

The Board of Education has published (Cd. 469I) its regulations for secondary schools. which are to come into force from August I next in England, excluding Wales and Monmouthshire. The regulations do not vary substantially from those of last year, except with regard to some points on which Sir Robert Morant lays special emphasis in his prefatory memorandum. The tendency of the regulations is towards allowing the school authorities greater liberty in planning the curriculum. The Board insists that the course of education shall be of a generous and civilising type, neither unduly specialised nor defective in essential elements. It must in all cases make adequate provision for instruction, among certain other subjects in physical science, including practical work by the pupils; and, as regards girls, must likewise include practical instruction in the elements of domestic subjects. Fo older girls science may be dropped, and mathematics re stricted to arithmetic, in order to make room for a fuller course in these domestic subjects. It is indicative of the growth of broader views among educationists and teachers to find the permanent secretary writing about the Board that it not only permits, but encourages, "such differentiation of type in relation to local needs as is consistent with a broad and solid general education, and such variation of instruction towards the particular needs and capacities of the pupils as does not interfere with the function of the school as a common organism directed towards the production of trained citizens."

THE annual report of the council of the City and Guilds of London Institute for the year' 1908 is provided with a series of exhaustive appendices containing reports by the dean of the City and Guilds Central Technical College, the principal of the Finsbury Technical College, the honorary secretary of the South London Technical Art No. 2069, VOL. 8o] 